\title{
Application of the Philosophical Concepts of Cognitive Linguistics in the Chinese Language Teaching of Foreign Scholars in China*
}

\author{
Chengjuan Wang ${ }^{1}$ \\ Luliang University
}

\begin{abstract}
This paper aims to examine current Chinese language teaching from the perspective of cognitive linguistics. It will not only help Chinese language researchers and foreign scholars in China make breakthroughs in Chinese language learning, but also be conducive to improving students' Chinese language learning ability. In the teaching of Chinese language, we should also stress the cultivation of students' overall language ability and cognitive ability, so as to improve the effectiveness both Chinese language teaching and learning.
\end{abstract}

\section{Keywords}

Cognitive Linguistics $•$ Chinese Scholars $•$ Chinese Language Teaching $\bullet$ Cognitive Linguistic Philosophy

\footnotetext{
* This work is one of the research results of the project: Humanities and Social Science Research project of the Education Department of Guangxi Zhuang Autonomous Region in 2014 - An innovative study on Chinese "moving object" structural word order from the perspective of word order typology (No.: YB2014558).

${ }^{1}$ Correspondence to: Chengjuan Wang (MA), Luliang University, Lvliang 033000, China. E-mail: m15935081041@163.com
} 
The emergence and development of cognitive linguistics has provided a new research perspective for philosophical circles, and a new inspiration to philosophy teaching. Philosophy occupies an important position in the cultivation of the comprehensive Chinese language teaching ability of foreign scholars in China (Chen \& Zhang, 2017; Xu \& Xu, 2017). Therefore, the study of philosophy teaching cannot be ignored. However, under the objectivist philosophy of language, the philosophy teaching in colleges and universities has always adopted traditional methods of philosophy teaching, which merely highlights the teaching of philosophical theories and tactics. As a result, students' cognitive ability and subjectivity in philosophical activities were not fully explored and utilized (Duan et al., 2015). The philosophical concept of cognitive linguistics emphasizes the importance of the subjective initiative of foreign scholars in China. When being applied to philosophical research, the theory of cognitive linguistics has its own advantages over objectivist linguistics in explanatory power and descriptiveness (Hall, Wicaksono, Liu, Qian \& Xu, 2017). Its guiding role in philosophical theory and practice are also increasingly evident (He \& Chen, 2017; Tripathy, 2010). This paper will probe into the enlightenment of the philosophical concept of cognitive linguistics on philosophy teaching in institutions of higher learning from the following aspects.

\section{The philosophical concept of cognitive linguistics}

\section{Cognitive linguistics}

Emerged in the 1980s, cognitive linguistics is "an interdisciplinary field that persists in the philosophical concept of "experience," with physical experience and cognition as the starting point, conceptual structure and meaning research as the core in the exploring of cognitive styles behind language facts, and making unified interpretation of language through cognitive styles and knowledge structures." Figure 1 shows source-related creativity of cognitive language.

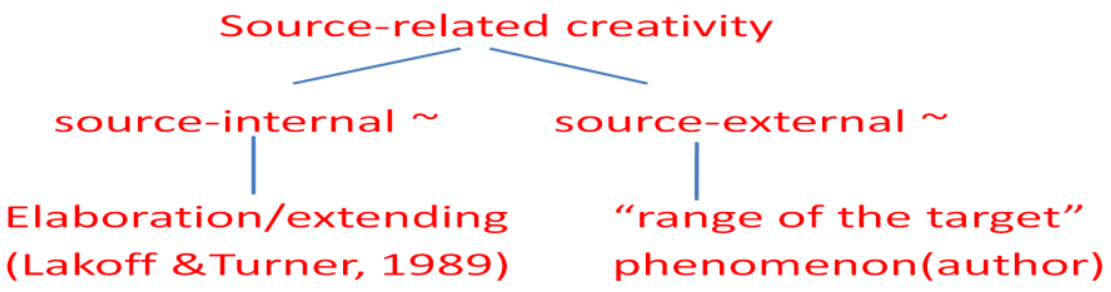

Figure1. Source-related creativity in linguistics.

\section{Student and teacher related principles}

\section{Highlight the students as the main body.}

Give full play to students' enthusiasm and creativity in classroom activities, so that students can participate, experience, summarize and reflect under the guidance of the teacher. Instead of merely a knowledge imparter, the teacher is also an organizer, leader, and participant (Koh, Burke, Luke, Gong \& Tan, 2018). The main 
position of teachers and students in the teaching process is interactive, with teachers playing a leading role, and students as the main body.

\section{Students of different English language proficiency need to participate extensively in activities}

English language classroom activities should be oriented toward all students and adapted to students' English language proficiency, application and demands. Real-world socializing context should be created for the involvement of all students.

\section{Students should have a clear position on themselves}

Many learners do not know enough about their own language learning situation, their own advantages and disadvantages, or what language learning strategies they can use to improve their learning efficiency. In the teaching process, teachers should strengthen students' understanding of their own cognitive styles and learning strategies so that the latter can correctly evaluate themselves and adapt to their own development and progress in language acquisition (Schoenfeld, 2016).

Reduce students' language learning anxiety and make them optimistic about the success or failure of learning

Teachers should cultivate students' love of language, inspire their learning motivation within, stress the role of affective strategies in learning, and relieve their learning anxiety (Tondeur, Van Braak, Ertmer, OttenbreitLeftwich, 2017; Lundberg et al., 2018). It is necessary to cultivate students' self-confidence, enhance their adventurous spirit for constant exploration of new knowledge, gaining new experiences, so that they will ultimately benefit from the success and happiness of language learning.

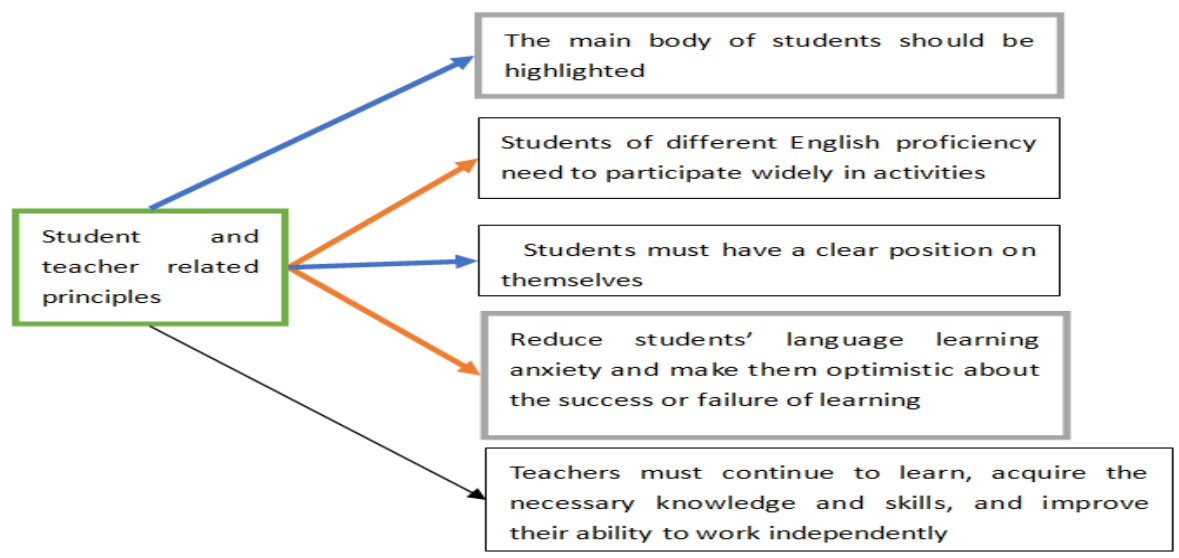

Figure 2. Student and teacher related principles. 
Teachers must continue to learn, acquire the necessary knowledge and skills, and improve their ability to work independently

In the teaching process, teachers are mainly responsible for such teaching tasks as organization, guidance, counseling, and motivation ( $\mathrm{Li}, 2018 ; \mathrm{Xu}, 2015)$. Therefore, they need to acquire inspiration and guidance from theoretical research, and sum up experiences and lessons from their own experiences before applying them to guide their new practice, hence gradually improving their teaching and research capabilities, and the ability to work independently. Student and teacher related principles as shown in Figure 2.

\section{The philosophy concept of language cognitive science}

The philosophical concept of cognitive linguistics stresses the interactive relationship between authors, works, and readers, and seeks "reasonable interpretation" and "philosophical harmony". For one thing, it acknowledges the restrictive effect of cognitive activities on philosophy, believing that translation is the result of experience and cognition. For the other, it points out that foreign scholars in China as one of the subjects of cognition should be constrained by the interaction between other cognitive subjects involved in philosophical activities. Philosophy should be a "creation with a range," and therefore it is also a dialectical, balanced philosophical concept. Figure 3 shows the language cognitive process of animals.

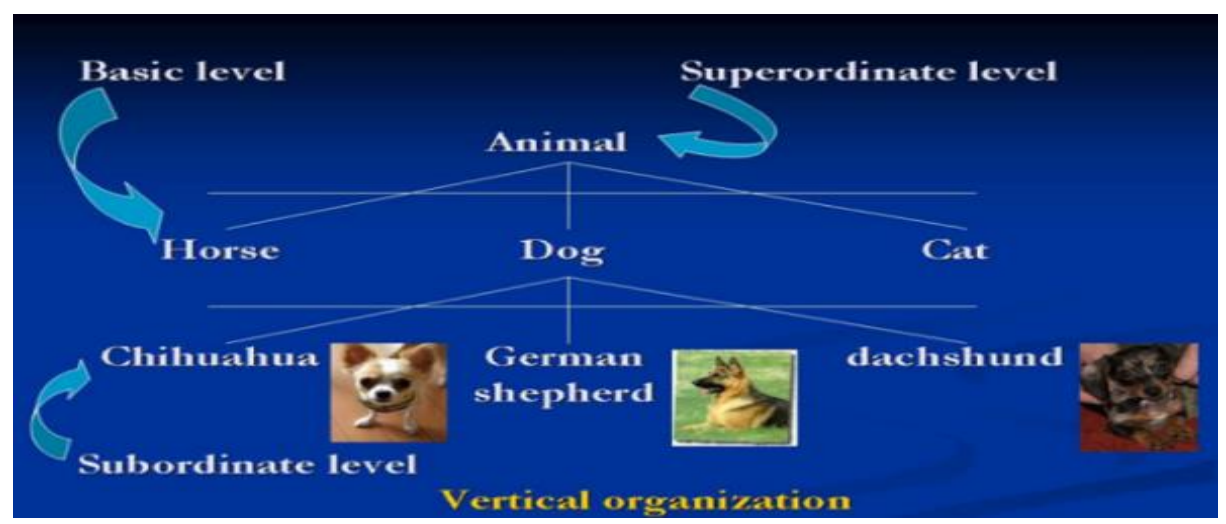

Figure 3. The process of animal Cognitive linguistics.

\section{Change of philosophy of language}

It is about what kind of philosophy is held for the language. Empiricism and rationalism are the cornerstones of traditional philosophy in the West. The conceptual structure is the symbol structure, and symbols obtain meaning through objective things, categories, features, and relationships in the objective world. Meaning is the "image representation of the external world in human psychology," or the fixed relationship between words and their meanings. Formalism and objective representation are the basis of symbolic operations. 


\section{Adopt a dynamic, open syllabus}

The syllabus should be developed based on teacher and student consultation, and constantly revised and supplemented to adapt to the changing teaching demands. The content of the teaching should satisfy the learners' needs in knowledge, intelligence, emotion, and personality.

\section{Provide students with rich, understandable language to input English classroom teaching content}

The content of English classroom teaching should be close connected to the students' actual life and the society. Teaching activities should allow students to be in scenarios similar to the life they are familiar with. The selection of learning materials can come from different registers and all walks of society.

\section{Pay attention to the development of learners' language communication competence}

In addition to general knowledge about the world, language communication skills should also include grammatical abilities, textual abilities, language abilities, language cultural abilities, and strategic abilities. Besides mastering language knowledge, students also need to develop their own skills in language and abilities in pragmatics and the utilization of learning strategies.

\section{Pay attention to the cultivation of students' autonomous learning ability}

Independent learning ability refers to students' ability to independently determine their learning objectives, learning process, as well as assess their learning Strategies such as pre-planning, self-monitoring, selfmanagement, self-assessment, and problem discovery play a big role in the development of their independent learning ability.

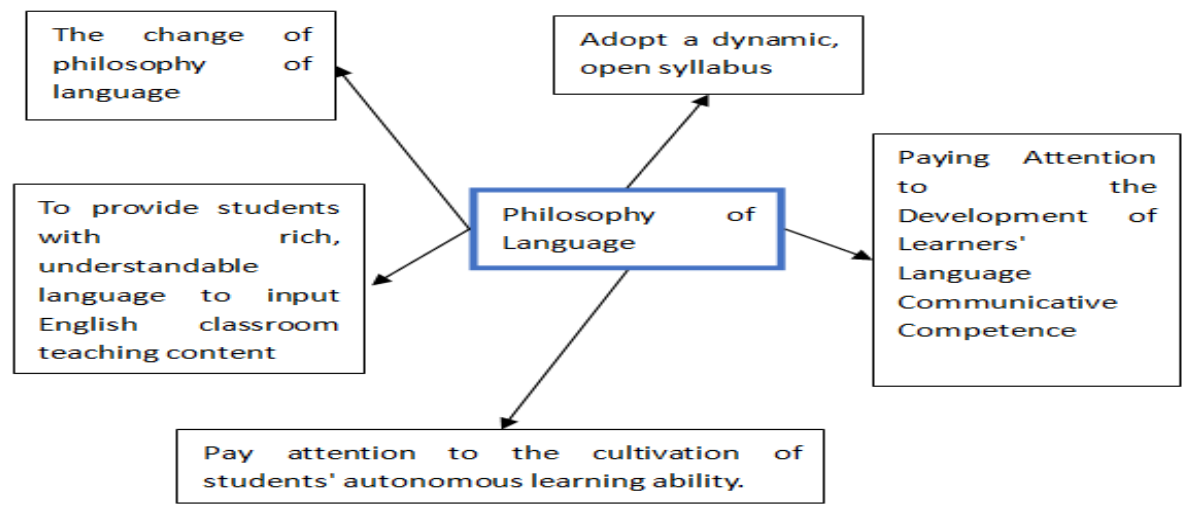

Figure 4. Philosophy of language.

\section{Teaching Design}

\section{Teaching goals and content}

The goal of this training is to enable foreign scholars engaged in Chinese language teaching to master the basic theoretical knowledge of educational information technology Internet application and how to make 
multimedia courseware. Through practical operation, they can apply what they learn to Chinese language teaching. In 2012, 2014 and 2016, Tianjin University successfully held multimedia Chinese language teaching and training programs for foreign scholars engaged in China language teaching, and has accumulated extensive experience. These trainings in China took more than a month, but this time, each training only lasts 3 days. The short teaching time and rich courses prove great challenges to training instructors. In order to successfully complete the teaching tasks, they made careful preparation before departure, and screened courses and content in accordance with previous experience, the information literacy level of these foreign scholars, and the time requirements of the training group. The preliminary curriculum plan is shown in Table 1.

Table 1

Original Course Schedule

\begin{tabular}{lcccc}
\hline & The first day & 2 days before & The first day & 2 days before \\
\hline Morning & Word & New words & PinYin & Idiom \\
Afternoon & ppt & Dialect & Computer & Poetry \\
\hline
\end{tabular}

\section{Learner analysis}

Table 2

Improved Course Schedule

\begin{tabular}{lcccc}
\hline & The first day & 2 days before & The first day & 2 days before \\
\hline Morning & Word in Chinese & New words & PinYin & Idiom \\
Afternoon & Ppt in Chinese & Dialect & Computer in Chinese & Poetry \\
\hline
\end{tabular}

The subject of this training is foreign scholars engaged in Chinese language teaching in primary and secondary schools. As they vary greatly in age, their levels of information literacy are uneven. Young teachers have a good grasp of information technology, while some senior teachers are weak in this aspect. In order to satisfy trainees with the content of the training, after fully consulting with the school, training instructors have listened to the school's suggestions and requirements, and made appropriate adjustments to courses and the content of the courses they teach. In particular, they made the "Teaching Design in the Courseware" to elaborate on teaching standards, principles and preparation methods of the courseware. The adjusted course plan is shown in Table 2 .

Table 3

Test Results between Raditional Methods and Cognitive Languages

\begin{tabular}{lccc}
\hline & Profession & Traditional methods (\%) & Cognitive linguistics (\%) \\
\hline \multirow{4}{*}{2012} & auto industry & 79 & 82 \\
& electronic & 80 & 84 \\
& medicine & 80 & 86 \\
biological & 85 & 90 \\
& Internet & 87 & 91 \\
& auto industry & 83 & 87 \\
electronic & 82 & 88 \\
& medicine & 85 & 89 \\
& biological & 86 & 92 \\
Internet & 89 & 94 \\
& auto industry & 89 & 92 \\
& electronic & 90 & 94 \\
& medicine & 89 & 96 \\
& biological & 90 & 95 \\
& Internet & 89 & 96 \\
\hline
\end{tabular}




\section{Project-based teaching design}

To highlight the training effect, the entire training courses have adopted project-based teaching. It refers to teaching activities conducted by teachers and students in the form of teamwork to jointly implement a complete "project" work. It breaks the conventional mode of "practice after learning," instead, it stresses "practice and learning," and "practice and then learning," so that students can exercise their abilities, explore knowledge, and sum up experiences while completing the tasks. Project-based teaching is generally based on practice, and supplemented by necessary theoretical guidance. Practical teaching mainly introduces image processing, animation production, and video processing, all being the basis for preparing materials for multimedia courseware. Using PPT or web pages as a tool for courseware integration, these materials are brought together. The guiding theory in this is the idea of courseware teaching design. The design of the entire course is shown in Figure 4. Table 3 and Figure 5 show the test results of the traditional methods and the cognitive language from 2012 to 2016.

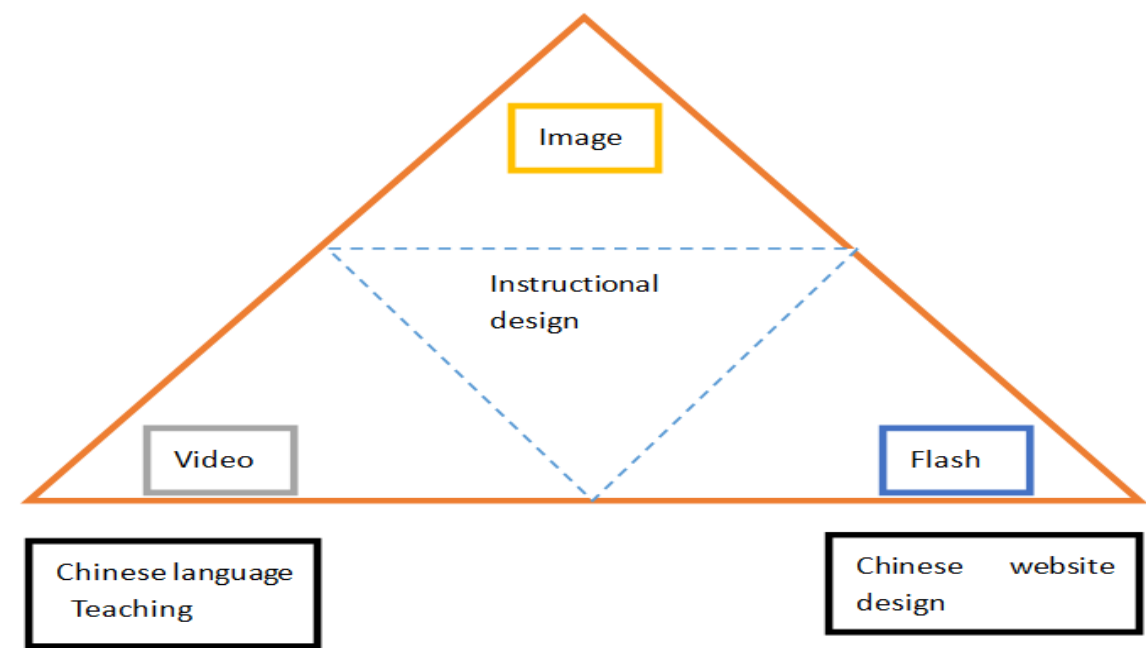

Figure 5. Chinese teaching course design.

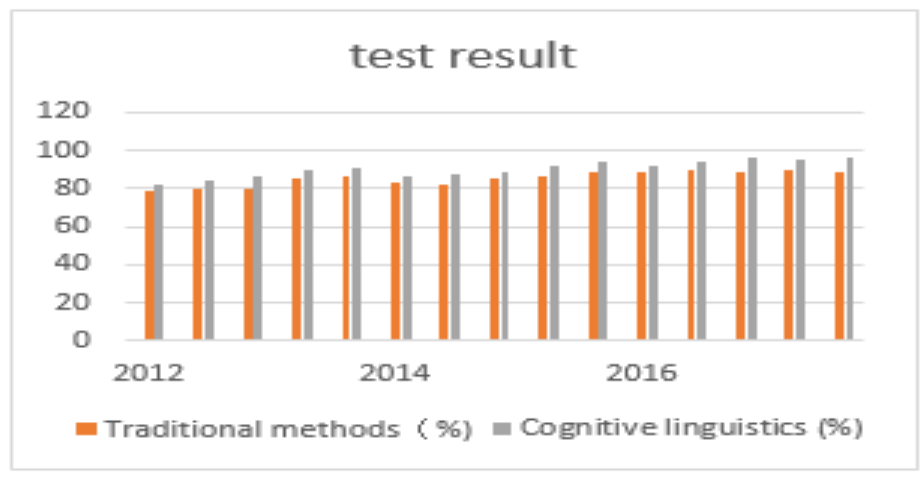

Figure 6. Test results of Chinese teaching course design. 


\section{Conclusion}

According to the philosophical concept of cognitive linguistics, philosophy is to be experienced. Such a trait requires that foreign scholars in China must acquire the knowledge needed by accessing rich philosophical materials. From the compilation of teaching materials, the most basic is to reflect, through the methodology, the cultivation of philosophical abilities as the goal. The research on the application of philosophical concepts in cognitive linguistics to the Chinese language teaching of foreign scholars should also incorporate content related to actual Chinese language teaching. In the teaching process, teachers should combine theory and practice. For foreign scholars in China, it will provide them with indirect experience, mobilize their enthusiasm, and enable them experience the entire process - from selection to completion of Chinese language teaching.

\section{References}

Chen, C., \& Zhang, L. J. (2017). An intercultural analysis of the use of hedging by Chinese and Anglophone academic English writers. Applied Linguistics Review, 8(1), 1-34. http://dx.doi.org/10.1515/applirev-20162009

Duan, C., Hill, C.E., Jiang, G., Hu, B., Lei, Y., \& Chen, J., Yu, L. (2015). The counselor perspective on the use of directives in counseling in China: Are directives different in China as in the United States. Counselling Psychology Quarterly, 28(1), 57-77. http://dx.doi.org/10.1080/09515070.2014.965659

Hall, C.J., Wicaksono, R., Liu, S., Qian, Y., \& Xu, X. (2017). Exploring teachers' ontologies of English: Monolithic conceptions of grammar in a group of Chinese teachers. International Journal of Applied Linguistics, 27(1), 87-109. http://dx.doi.org/10.1111/ijal.12107

He, L., \& Chen, D. (2017). Developing common listening ability scales for Chinese learners of English. Language Testing in Asia, 7(1), 4. http://dx.doi.org/ 10.1186/s40468-017-0033-4

Koh, K., Burke, L.E.C.A., Luke, A., Gong, W., \& Tan, C. (2018). Developing the assessment literacy of teachers in Chinese language classrooms: A focus on assessment task design. Language Teaching Research, 22(3), 264-88. http://dx.doi.org/ 10.1177/1362168816684366

Li, F.F. (2018). Research method innovation of college students' ideological and political education based on cognitive neuroscience. Neuro Quantology, 16(5), 1303-1306. http://dx.doi.org/ 10.14704/nq.2018.16.5.1269

Lundberg, J., Arvola, M., Westin, C., Holmlid, S., Nordvall, M., \& Josefsson, B. (2018). Cognitive work analysis in the conceptual design of first-of-a-kind systems - Designing urban air traffic management. Behaviour \& Information Technology, 37(9), 904-925. https://dx.doi.org/10.1080/0144929X.2018.1505951

Schoenfeld, A.H. (2016). Learning to think mathematically: Problem solving, metacognition, and sense making in mathematics (Reprint). Journal of Education, 196(2), 1-38.

Tondeur, J., van Braak. J., Ertmer, P.A., Ottenbreit-Leftwich. A. (2017). Understanding the relationship between teachers' pedagogical beliefs and technology use in education: a systematic review of qualitative evidence. Educational Technology Research and Development, 65(3), 555-75. http://dx.doi.org/10.1007/s11423-016-9492-z 
Tripathy, M. (2010). Power transformer differential protection using neural network principal component analysis and radial basis function neural network. Simulation Modelling Practice \& Theory, 18(5), 600-611. http://dx.doi.org/10.1016/j.simpat.2010.01.003

Xu, Y.F., Xu, J.X. (2017). On China's excellent traditional culture and innovation of ideological and political education in colleges and universities. Advances in Social Science, Education and Humanities Research, 106(24), 230-234. http://dx.doi.org/10.2991/icesem-17.2017.51

$\mathrm{Xu}, \mathrm{Z}$. (2015). The past, present and future of Chinese MA theses in interpreting studies: $A$ scientometric survey. Perspectives, 23(2), 284-304. http://dx.doi.org/10.1080/0907676X.2015.1011175 